\title{
Public opinion on smoke-free policies in restaurants and predicted effect on patronage in Hong Kong
}

\author{
T H Lam, M Janghorbani, A J Hedley, S Y Ho, S M McGhee, B Chan
}

Tobacco Control 2002;11:195-200

See end of article for authors' affiliations

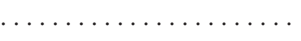

Correspondence to: Professor A J Hedley, Department of Community Medicine and Unit for Behavioural Sciences, University of Hong Kong Medical Centre, 21 Sassoon Road, Hong Kong;

commed@hkucc.hku.hk

Received 18 August 2001 and revision requested 12 November 2001 Accepted 25 April 2002
Background: The Hong Kong government has proposed legislation for smoke-free policies in all restaurants and bars. This is opposed by certain sections of the catering industry.

Objective: To assess public opinion on smoke-free restaurants and to estimate changes in patronage. Design: A population based, cross sectional random digit dialling telephone survey conducted from November 1999 to January 2000.

Setting and participants: 1077 randomly selected subjects age 15 years or over (response fraction of $81.6 \%)$.

Results: $68.9 \%$ (95\% confidence interval (CI) $66.2 \%$ to $71.7 \%$ ) supported a totally smoke-free policy in restaurants. Experiences of discomfort or symptoms from second hand smoke in restaurants were common. The majority $(77.2 \%, 95 \% \mathrm{Cl} 74.7 \%$ to $79.7 \%)$ anticipated no change in their frequency of use of restaurants after a smoke-free policy. Increased use was predicted by $19.7 \% 195 \% \mathrm{Cl} 17.3 \%$ to $22.1 \%)$ of respondents, whereas $3.2 \%(95 \% \mathrm{Cl} 2.2 \%$ to $4.4 \%)$ stated that they would dine out less often. In multivariate analyses, non-smokers (adjusted odds ratio (OR) 4.9), people who ate three times or less per week in restaurants as compared to those who ate $>10$ times per week (OR 2.1), those who had previous experience of discomfort from exposure to passive smoking in restaurants (OR 2.8), or who had avoided restaurants in the past because of smoking (OR 1.9), were more likely to support a totally smoke-free policy in restaurants. Smoke-free policies do not appear to have an adverse effect on restaurants, and may increase business by a considerable margin.

Conclusion: This comprehensive survey-the first in Asia-shows strong community support for smoke-free dining and predicts an overall increase in the patronage of restaurants after the introduction of legislation for totally smoke-free restaurants.
R estaurants are one of the most frequently visited public places where both smokers and non-smokers are involuntarily exposed to second hand smoke and the risk of serious adverse health effects. ${ }^{1}$ In Western developed countries, there is increasing concern about the health effects of passive smoking in restaurants among both patrons and employees. In the past decade an increasing number of studies in the West have indicated strong public support for smoke-free restaurants, ${ }^{2-10}$ but no studies have been reported from Asia. Although legislation banning smoking in bars and restaurants has been enacted in some developed countries, including Australia, New Zealand, France, and many states of the USA, ${ }^{25-12}$ relatively little has been done in developing countries, where the problem is often much greater.

Since 1998, legislation in Hong Kong requires restaurants with more than 200 seats to designate at least one third of the seats as a no smoking area. However, the tobacco industry and many restaurant owners have consistently opposed proposals to restrict smoking in restaurants, arguing that smoke-free policies will result in a loss of business. This argument assumes that if smoking is totally banned, smokers will not dine out as often, despite good evidence from the USA, Canada, and Australia that turnover is not affected or has increased. ${ }^{6813-23}$ In June 2001 the Hong Kong Special Administrative Region government presented new legislative proposals for completely smoke-free restaurants and bars. ${ }^{24}$ More evidence is needed on public preferences for smoke-free dining to support this area of tobacco control.

The aims of the survey were to assess public opinion on totally smoke-free restaurant policies, the frequency of restaurant use among smokers and non-smokers, and the self reported predictions of change in the frequency of restaurant use under smoke-free policies among Hong Kong adults.
These data were used to assess the possible impact of a totally smoke-free policy on the business of restaurants and were submitted to the government as part of the consultation process on the new legislative proposals.

\section{SUBJECTS AND METHODS Background}

Hong Kong is an economically advanced post-industrial Special Administrative Region, in southern China, with a population of 6.8 million, 95\% of whom are ethnic Chinese. As Hong Kong has almost universal telephone coverage for all households, ${ }^{25}$ estimated at $99 \%$ after allowing for multiple lines (Dr J BaconShone, personal communication) telephone interviews are the most cost effective method to measure public opinion.

\section{Subjects}

The study population consisted of the Cantonese speaking adult population of Hong Kong, aged 15 years or above. A two stage random sample was obtained. The sample units in the first stage were households. Each eligible household was contacted by random digit dialling, ${ }^{26}$ in which the last three numbers of the eight digit telephone number, which were selected by a simple random sampling method from telephone directories, were randomly generated using computer programs. Non-household numbers and those which were not in use were excluded. The second stage was to select randomly one subject aged 15 years or over within each eligible household. After telephone contact and self introduction, the interviewer explained the purposes of the study and oral consent was sought. The adult who answered the telephone was asked how many people aged 15 or above were living in that household. All eligible adults were listed, from the oldest to the youngest. One person was randomly 
selected for interview using the Kish grid. ${ }^{27}$ No substitutions were allowed, and repeated call backs (maximum of 15) at different times of the day and on different days of the week were made if the selected person was not available. From November 1999 to January 20001320 eligible households were contacted; $169(12.8 \%)$ of the 1320 selected subjects within these households could not be contacted and 74 (5.6\%) households rejected the interview or had an answering machine. A total of 1077 subjects completed the interviews giving a response fraction of $81.6 \%(1077 / 1320)$.

\section{Interview method}

The questionnaire included sociodemographic characteristics (age, sex, education, marital status, place of birth, monthly income, and type of housing), tobacco use, as well as knowledge, attitudes, and beliefs toward smoking and passive smoking, frequency of eating in restaurants, past history of having avoided restaurants either because of tobacco smoke or because of smoke-free policies, and experiences of symptoms or discomfort from passive smoking in restaurants. The subjects were asked whether they agreed or not that the government should legislate to ban smoking completely in all restaurants and to predict how a smoke-free policy would affect their frequency of eating in restaurants in the future. Each interview took about 10 minutes to complete.

A current smoker was defined as one who now smoked at least one cigarette per day (at least seven cigarettes per week). Those who smoked less than one cigarette per day or seven cigarettes per week were designated as occasional smokers. Those who had never smoked at all, or smoked less than one cigarette per day for less than six months but had quit, were designated as never smokers, and those who had smoked at least one cigarette per day for at least six months but had quit were designated as ex-smokers.

\section{Analysis}

Means (SD) are presented for continuous variables, and the 95\% confidence interval (CI) for differences between means and proportions was estimated by confidence interval analysis software. ${ }^{28}$ Significance was assessed by $\chi^{2}$ tests. To examine the predictors of support for smoke-free policies, forward stepwise binary logistic regression was carried out to calculate multi adjusted odds ratios (OR) and the $95 \%$ CI of OR with the SPSS for Windows LR procedure. ${ }^{29}$ Predictors examined included the participant's age, sex, education, smoking pattern, marital status, number of times eating in restaurants per week, previously avoided restaurants because of smoking, and experience of symptoms and discomfort. All tests for significance were two tailed, with the level of significance at $\mathrm{p}<0.05$.

\section{RESULTS}

\section{Subject characteristics}

There were $522(48.5 \%)$ males and 555 (51.5\%) females, aged 15-84 years with a mean (SD) age of 40.4 (15.6) years and a median of 40 years. Twenty three per cent had primary or lower education and $20.5 \%$ had university education. The sample had similar distributions in sex, age, place of birth, and marital status as those in the Hong Kong population ${ }^{30}$ (absolute differences less than five percentage points). However, slightly more of our subjects had tertiary education than the Hong Kong population (20.5\% v 15.2\%). The proportion of daily smokers among the sample $(12.3 \%, 95 \%$ CI $10.4 \%$ to $14.3 \%$ ) was slightly less than that estimated by the Government Household Survey in the general population ${ }^{31}$ $(13.9 \%)$ in 2000

\section{Smoking pattern}

Seven hundred and sixty two $(70.8 \%, 95 \%$ CI $68.0 \%$ to $73.5 \%)$ respondents were never smokers, 133 ( $12.3 \%, 95 \%$ CI $10.4 \%$ to
$14.3 \%)$ were daily smokers, and $24(2.2 \%, 95 \%$ CI $1.4 \%$ to $3.3 \%)$ were occasional smokers, while 158 (14.7\%, 95\% CI $12.6 \%$ to $16.8 \%)$ were ex-smokers. More males $(21.8 \%)$ than females $(3.4 \%)$ smoked daily $(\mathrm{p}<0.001)$. For the analyses below, never smokers and ex-smokers were grouped as non-smokers and daily and occasional smokers, as current smokers. A higher proportion of smokers than non-smokers reported patronage of restaurants (table 1). Equal proportions of smokers and non-smokers reported visiting restaurants with children.

The majority of both non-smokers and smokers reported that they believed passive smoking can cause lung cancer and is harmful to the health of children and adults, but non-smokers' reactions were significantly more negative towards passive smoking than smokers. More than half of non-smokers $(56.1 \%, 95 \%$ CI $52.9 \%$ to $59.3 \%)$ compared with just over a quarter of smokers (28\%, 95\% CI $21.0 \%$ to $35.1 \%)$ had avoided a restaurant because of smoking (table 1).

\section{Attitudes to smoke-free policies, knowledge, and experiences}

Seven hundred and thirty seven $(68.9 \%$, 95\% CI $66.2 \%$ to $71.7 \%)$ subjects "agreed or strongly agreed" that the government should introduce a totally smoke-free policy covering all restaurants.

The majority $(77.2 \%, 95 \%$ CI $74.7 \%$ to $79.7 \%)$ of respondents anticipated no change in their patronage of restaurants if there was a totally smoke-free policy. Almost one in five (19.7\%, 95\% CI $17.3 \%$ to $22.1 \%$ ) indicated that they would dine out more often, and only $3.2 \%$ (95\% CI $2.2 \%$ to $4.4 \%$ ) would decrease their patronage. Twenty per cent of smokers would dine out less often but $22.5 \%$ of non-smokers would dine out more often (table 1 ).

Only $8.0 \%$ (95\% CI $6.4 \%$ to $9.8 \%$ ) of respondents reported that currently they either did not eat out, or ate out less than once a week. In this subgroup $22.1 \%$ (95\% CI $13.9 \%$ to $32.3 \%$ ) of respondents indicated that if restaurants were smoke-free, they would dine out more.

A substantial proportion of respondents expressed concern about passive smoking. Fifty two per cent (95\% CI $49.0 \%$ to $55.0 \%)$ reported having left a restaurant because of tobacco smoke, $28 \%$ of whom were smokers. In contrast, only $3.6 \%$ (95\% CI $2.6 \%$ to $4.9 \%$ ) of respondents (nearly all of them smokers) reported having avoided going to a restaurant because smoking was not permitted.

The respondents' knowledge about the health risks associated with active and passive smoking and levels of experience of discomfort and symptoms from exposure to passive smoking was high. Ninety seven per cent agreed that smoking is hazardous to health. Although few knew that smoking can cause impotence in males $(13.9 \%)$, about half knew that smoking can result in increased skin aging (52.7\%).

Ninety one per cent (95\% CI $88.9 \%$ to $92.5 \%$ ) "often or sometimes" experienced at least one discomfort or feeling of dissatisfaction, and $47.4 \%$ (95\% CI $44.4 \%$ to $50.4 \%$ ) "often or sometimes" experienced at least one symptom. During the past one month, $69.4 \%$ (95\% CI $66.6 \%$ to $72.1 \%$ ) reported that they were "often or sometimes" exposed to second hand smoke in restaurants (table 2).

Support for totally smoke-free restaurants was higher in women $(75.6 \%)$ than men $(61.8 \%)$, in married $(70.9 \%)$ rather than single $(63.9 \%)$ individuals, in non-smokers $(75.7 \%)$ than smokers $(29.0 \%)$, and in people who had avoided restaurants in the past because of smoking or had past experience of discomfort or symptoms from passive smoking in restaurants (table 3).

Although support for a totally smoke-free policy was related to smoking status, it was not related to the number of cigarettes smoked.

To determine the predictors of respondents' support for a totally smoke-free policy (agree or strongly agree $=1$, 
Table 1 Knowledge, attitudes, and behaviours in relation to smoke-free policies in restaurants by smoking status, Hong Kong

\begin{tabular}{|c|c|c|c|c|}
\hline Variables & $\begin{array}{l}\text { Non-smokers } \\
\mathrm{n}=920(\%)\end{array}$ & $\begin{array}{l}\text { Smokers } \\
n=157(\%)\end{array}$ & $\chi^{2}$ & $\mathrm{p}$ Value \\
\hline Number of times eating in restaurant/week & & & 25 & $<0.0001$ \\
\hline$<1$ & 8.8 & 3.2 & & \\
\hline $1-3$ & 29.3 & 19.7 & & \\
\hline $4-6$ & 25.4 & 21.7 & & \\
\hline $7-10$ & 24.9 & 33.1 & & \\
\hline$>10$ & 11.5 & 22.3 & & \\
\hline $\begin{array}{l}\text { Number of times eating in restaurant with } \\
\text { children/week }\end{array}$ & & & 3.8 & 0.42 \\
\hline$<1$ & 58.6 & 62.4 & & \\
\hline $1-3$ & 34.0 & 28.7 & & \\
\hline $4-6$ & 4.5 & 5.7 & & \\
\hline $7-10$ & 2.4 & 1.3 & & \\
\hline$>10$ & 0.5 & 2.3 & & \\
\hline $\begin{array}{l}\text { Anticipated change in patronage if there were } \\
\text { total ban on smoking }\end{array}$ & & & 198.2 & $<0.0001$ \\
\hline More often & 22.5 & $3.2^{*}$ & & \\
\hline Less often & 0.2 & 20.4 & & \\
\hline Just as often & 77.3 & 76.4 & & \\
\hline \multicolumn{5}{|l|}{ Agree that passive smoking: } \\
\hline causes lung cancer & 79.9 & $61.1^{*}$ & & \\
\hline causes heart disease & 93.5 & 54.8 & & \\
\hline causes fetal growth retardation & 93.5 & 87.9 & & \\
\hline harms children's health & 96.1 & 89.8 & & \\
\hline causes ill health & 97.4 & 91.7 & & \\
\hline Ever avoided a smoky restaurant & 56.1 & $28.0^{*}$ & & \\
\hline Ever avoided a totally smoke-free restaurant & 0.3 & $22.9^{*}$ & & \\
\hline
\end{tabular}

disagree, strongly disagree or no opinion $=0$ ), stepwise binary logistic regression was computed to test nine independent variables (table 3 ). The final model selected five significant predictors. Non-smokers, people who ate three times or less per week in restaurants, those who had avoided restaurants because of smoking, and those who had had experiences of discomfort or dissatisfaction from exposure to passive smoking in restaurants were more likely to support a totally smoke-free policy. There was no consistent trend for educational level. Those with primary or tertiary level education were more likely to support a smoke-free policy than those with secondary schooling. Non-smokers were about five times as likely as smokers to support a smoke-free policy (OR 4.8 ). The other variables tested were not significant predictors.

\section{Impact on patronage}

In December 2000 the estimated population aged 15 years or older in Hong Kong was 5691 582; this figure was used to

\begin{tabular}{ll}
\hline $\begin{array}{l}\text { Table } 2 \text { Experiences and symptoms following second hand smoke exposures in } \\
\text { restaurants }\end{array}$ & $\mathrm{n}=1077(\%, 95 \% \mathrm{Cl})$ \\
\hline & $69.4(66.6$ to 72.1$)$ \\
\hline & \\
\hline & $82.5(80.2$ to 84.7$)$ \\
Exposure to second hand smoke in restaurant in past month* & $60.9(58.0$ to 63.8$)$ \\
Bad smell from second hand smoke & $50.8(47.8$ to 53.8$)$ \\
Second hand smoke affected appetite & $27.9(25.3$ to 30.6$)$ \\
Tobacco odour stayed on clothes or hair & $25.3(22.8$ to 27.9$)$ \\
Had a bad impression of that restaurant & $62.9(60.0$ to 65.7$)$ \\
Thought of avoiding that restaurant in the future & $57.8(54.8$ to 60.7$)$ \\
Thought of finding another seat to escape from the smoke & \\
Finished the meal fast and left that restaurant & \\
Experiences of symptoms* & $8.5(6.9$ to 10.4$)$ \\
Dizziness or headache & $16.0(13.8$ to 18.2$)$ \\
Eye irritation & $24.8(22.2$ to 27.4$)$ \\
Nose irritation, running nose, sneezing & $24.7(22.1$ to 27.3$)$ \\
Throat irritation, sore throat & $22.9(20.4$ to 25.4$)$ \\
Cough or phlegm & $1.7(1.0$ to 2.6$)$ \\
Asthma or wheezing & $12.6(10.6$ to 14.6$)$ \\
Difficulty in breathing & \\
\hline *Proportion of respondents who often or sometimes had that feeling or experience from second hand smoke \\
in restaurants in the past one month. \\
\hline
\end{tabular}


Table 3 Predictors for support of totally smoke-free policy in restaurants

\begin{tabular}{|c|c|c|c|c|}
\hline & & $\begin{array}{l}\text { Support for smoke-free } \\
\text { policies (number (\%)) }\end{array}$ & $\begin{array}{l}\text { Crude odds ratio } \\
(95 \% \mathrm{Cl})\end{array}$ & $\begin{array}{l}\text { Adjusted odds ratio } \\
(95 \% \mathrm{Cl})\end{array}$ \\
\hline All subjects & & $737(68.9)$ & - & - \\
\hline \multirow[t]{2}{*}{ Sex } & Male & $321(61.8)$ & 1.0 & - \\
\hline & Female & $416(75.6)$ & 1.9 (1.5 to 2.5$)$ & NS \\
\hline \multirow[t]{6}{*}{ Age (years) } & $<20$ & $58(62.4)$ & 1.0 & NS \\
\hline & $20-29$ & $96(60.0)$ & $0.9(0.5$ to 1.6$)$ & - \\
\hline & $30-39$ & $190(67.6)$ & $1.3(0.8$ to 2.1$)$ & - \\
\hline & $40-49$ & $179(72.5)$ & $1.6(0.9$ to 2.7$)$ & - \\
\hline & $50-59$ & $88(73.3)$ & $1.7(0.9$ to 3.1$)$ & - \\
\hline & $\geqslant 60$ & $121(74.2)$ & $1.7(0.97$ to 3.1$)$ & - \\
\hline \multirow[t]{3}{*}{ Education } & Primary or lower & $176(72.7)$ & 1.0 & 1.0 \\
\hline & High school & $390(64.6)$ & $0.7(0.5$ to 0.95$)$ & $0.7(0.5$ to 0.9$)$ \\
\hline & University & 167 (76.3) & $1.2(0.8$ to 1.9$)$ & $1.1(0.6$ to 1.7$)$ \\
\hline \multirow[t]{2}{*}{ Smoking status } & Smokers & $45(29.0)$ & & \\
\hline & Non-smokers & $691(75.7)$ & $7.6(5.1$ to 11.3$)$ & 4.9 (3.3 to 7.4$)$ \\
\hline \multirow{3}{*}{ Marital status } & Never married & $205(63.9)$ & 1.0 & NS \\
\hline & Now married & $492(70.9)$ & 1.4 (1.03 to 1.8$)$ & - \\
\hline & Divorced/separated & $38(74.5)$ & $1.7(0.8$ to 3.4$)$ & - \\
\hline \multirow{4}{*}{$\begin{array}{l}\text { Number of times eating in } \\
\text { restaurant/week }\end{array}$} & $>10$ & $81(58.3)$ & 1.0 & 1.0 \\
\hline & $7-10$ & $179(63.7)$ & $1.3(0.8$ to 1.9$)$ & $1.2(0.7$ to 1.9$)$ \\
\hline & $4-6$ & $178(67.2)$ & 1.5 (0.9 to 2.3$)$ & $1.3(0.8$ to 2.1$)$ \\
\hline & $\leqslant 3$ & $299(77.9)$ & 2.5 (1.7 to 3.8$)$ & $2.1(1.3$ to 3.4$)$ \\
\hline \multirow[t]{2}{*}{ Avoided restaurant because of smoke } & No & $299(59.6)$ & 1.0 & 1.0 \\
\hline & Yes & $429(77.0)$ & $6.1(2.7$ to 14.1$)$ & 1.9 (1.4 to 2.5$)$ \\
\hline \multirow{2}{*}{$\begin{array}{l}\text { Experiences of discomfort or } \\
\text { dissatisfaction* }\end{array}$} & No & $34(35.1)$ & 1.0 & 1.0 \\
\hline & Yes & 703 (72.3) & 4.8 (3.1 to 7.5$)$ & 2.8 (1.6 to 4.7$)$ \\
\hline \multirow[t]{2}{*}{ Experiences of symptoms* } & No & $346(61.6)$ & 1.0 & NS \\
\hline & Yes & $391(77.1)$ & 2.1 (1.6 to 2.8$)$ & - \\
\hline
\end{tabular}

illustrate the total number among the public who might change their usual patterns of eating out (table 4). The $20 \%$ (95\% CI $17.3 \%$ to $22.1 \%$ ) who would eat out more often contributed a total of 6260740 dining out visits per week at their current average rate of 5.5 meals per week each. If this group increased their number of dining out visits per week by only one per person on average, this would lead to the consumption of 1.13 million additional meals. If the number of extra visits to restaurants is as high as four times a week, then the additional meals would amount to about 4.5 million per week (table 4 ). The $3 \%$ (95\% CI $2.2 \%$ to $4.4 \%$ ) who stated that they would eat out less made 1639175 dining out visits at an average of 9.6 meals per week each. If after a smoking ban this group eat out on average 1-4 times less than before, then the drop in meals consumed would range from 170747 to 682988 . Under the assumption of an extreme change in pattern of eating out, with the increase in dining visits amounting to only one per week (in $20 \%$ of the population) and the reduction in visits being four per week (in 3\% of the population), there would still be a net gain of 455328 extra meals per week under a totally smoke-free policy; a gain in business of about $1.3 \%$. The estimates of eating out patterns based on the responses of individuals will predictably underestimate the actual numbers of additional meals as a result of smoke-free policies, because most diners are likely to eat with other members of their households or friends.

\section{DISCUSSION}

Much public debate has taken place on the need for totally smoke-free restaurants. Our analysis of a sample of Hong
Kong adults clearly indicates a strong community desire for totally smoke-free dining and that smoke-free policies are likely to increase overall patronage of restaurants in Hong Kong. Although there are similar results from previous studies, ${ }^{13} 142331$ the present report is the first comprehensive survey on this issue in Asia. Our findings have provided the government with a reliable assessment of the public's opinion to support stronger and more comprehensive tobacco control measures including totally smoke-free policies for restaurants, bars, and other indoor workplaces. ${ }^{24}$

We found no clear effects of age, sex, and marital status on support for a total ban. The respondents had high level of knowledge of the health hazards of both active and passive smoking, although some important gaps remain and should be addressed. However, although a knowledgable population and a high level of awareness of the health risks might appear to be a necessary basis for majority support for smoke-free policies, we found that current levels of individual knowledge were not significant predictors of support when other covariates were considered. Instead, previous experiences or behaviours were strong predictors. For example, those who dined out most infrequently, who had had bad experiences, or either had been prompted to leave a restaurant because of smoke or had avoided smoky restaurants, were most likely to be supportive.

These results suggest that public health advocacy for support of smoke-free policies should aim to help individuals to internalise general knowledge into their health awareness, experiences, and behaviours. Immediate experiences of discomfort and symptoms from second hand smoke in 
Table 4 Effect of change in patterns of eating out on gain or loss in number of meals sold per week, based on 5691582 individuals in the population aged 15 years or over

\begin{tabular}{|c|c|c|}
\hline $\begin{array}{l}\text { Declared change in eating out } \\
\text { pattern }\end{array}$ & Current pattern of eating out & $\begin{array}{l}\text { Effect of change in eating out pattern on number of meals } \\
\text { gained or lost }\end{array}$ \\
\hline $\begin{array}{l}\text { Would eat out more: } 20 \% \text { of the } \\
\text { survey respondents who eat out } \\
\text { on average } 5.5 \text { times per week }\end{array}$ & $\begin{array}{c}5691582 \text { population } \\
20 \% \text { who would go more often } \\
\text { * } \\
5.5 \text { times eat out per week now } \\
= \\
6260740 \text { total current eating out visit/week }\end{array}$ & $\begin{array}{l}+1 \text { time } / \text { week }=1138316 \text { extra meals } \\
+2 \text { time } / \text { week }=2276632 \text { extra meals } \\
+3 \text { time } / \text { week }=3414948 \text { extra meals } \\
+4 \text { time } / \text { week }=4553264 \text { extra meals } \\
\text { Range: } 1.13 \text { million to } 4.5 \text { million additional meals consumed } \\
\text { per week }\end{array}$ \\
\hline $\begin{array}{l}\text { Would eat out less: } 3 \% \text { of the } \\
\text { survey respondents who eat out } \\
\text { on average } 9.6 \text { times per week }\end{array}$ & $\begin{array}{c}5691582_{*} \text { population } \\
3 \% \text { who would go less often } \\
\text { * } \\
9.6 \text { times eat out per week now } \\
= \\
1639175 \text { total current eating out visit/week }\end{array}$ & $\begin{array}{l}-1 \text { time } / \text { week }=170747 \text { fewer meals } \\
-2 \text { time/week }=341495 \text { fewer meals } \\
-3 \text { time/week }=512242 \text { fewer meals } \\
-4 \text { time/week }=682988 \text { fewer meals } \\
\text { Range: } 170000 \text { to } 683000 \text { fewer meals consumed/week }\end{array}$ \\
\hline $\begin{array}{l}\text { Would not change: } 77 \% \text { of the } \\
\text { survey respondents who eat out } \\
\text { on average } 6.2 \text { times per week }\end{array}$ & $\begin{array}{c}5691582 \text { population } \\
77 \% \text { who would not change } \\
\text { * } \\
6.2 \text { times eat out per week now } \\
= \\
27171612 \text { total current eating out visit/week }\end{array}$ & No change \\
\hline All groups & Total number of eating out visit/week = 35173975 & $\begin{array}{l}\text { Under the most conservative (worst case) assumption that } 20 \% \\
\text { only eat out once more often and } 3 \% \text { eat out } 4 \text { times less often } \\
\text { there would be a net gain of } 1138316-682988=455328 \\
\text { meals consumed/week; a gain in business of } 1.3 \%\end{array}$ \\
\hline
\end{tabular}

restaurants are common but could have been accepted or ignored by the majority. People need to be prompted to respond when they are exposed to second hand smoke, and to voice their feelings of discomfort caused by the exposure. Armed with the knowledge that second hand smoke can cause serious long term harm in addition to immediate discomfort, potential customers would be more strongly motivated to avoid further exposure by avoiding restaurants which allow smoking. The next step is to promote greater population demand for smoke-free dining when people visit restaurants. When such attitudes and behaviours have become common, we anticipate there will be even stronger support for legislation on smoke-free restaurants and other public places.

As expected, smoking status was among the strongest predictors for support for smoke-free policies. When given a choice, non-smokers were more likely to want restaurants to be totally smoke-free, while smokers were more likely to prefer a separate smoking area. However, as in other surveys, ${ }^{39}$ some smokers $(29 \%)$ also supported a totally smoke-free policy. Although smokers were more likely than non-smokers to say they would dine out less often if a smoking ban was introduced, most smokers' (76\%) would not change their dining out frequency. As there were more non-smokers in the population and $23 \%$ of them would go more often, the predicted net result would be an increase in patronage. These results are consistent with those of previous studies based on self reports, which predicted changes in frequency of restaurant use among adults after implementation of a smoke-free policy, and with reports from the USA, Australia, and Canada of either predicted or actual increases in business. ${ }^{6}{ }^{13-21} 32$ No similar studies have been reported in Asia on predicted or real changes in restaurant business after a total ban. Using a conservative approach, we estimated a net increase of $1.3 \%$ in business, or 455328 extra meals per week. A sensitivity analysis, based on the lower bound of the confidence interval of the proportion who would dine out more and the upper bound for those who would dine out less, gave a neutral or marginally positive result with the increase in busi- ness reduced to $0.03 \%$. In New York, Corsun and colleagues ${ }^{33}$ found there was no overall negative impact, with the increased revenue from patrons favouring smoke-free dining balancing the loss from those who withdrew.

The findings confirm that Hong Kong restaurant owners could expect an increase in customers if smoking is banned in all restaurants, because the proportion of people who would go more often is much greater than the proportion who would go less, while the great majority will not change their frequency. The fear of losing business is not supported by this estimate on predicted changes before legislation here nor the actual changes reported elsewhere after legislation.

Administration of the interview by unblinded investigators could have biased our subjects' responses, although the use of structured questionnaires and standardised interview techniques should have minimised interview bias. Our findings must be interpreted with some caution since respondents were reporting behavioural intentions in response to a hypothetical event. The $82 \%$ response fraction was high for telephone surveys, but we had no data to check for non-response bias. Slight differences in education between study participants and the entire population of Hong Kong could limit slightly the generalisability of our findings, but this was controlled for in the calculation of predictors.

The economic impact of legislation for totally smoke-free restaurants is a critical issue for policymakers concerned about second hand smoke exposures of customers and employees. Assessment of the potential economic impact of such legislation should be based on objective evidence available from consumers in the general population and not simply from the speculation of restaurant owners, many of whom have apparently been influenced by predictions of harm to their business by the tobacco industry. Before the new law is brought into force, the only feasible way to assess the impact on business is by assessing predicted changes in patronage. These findings from public surveys in Hong Kong and predictions of the impact of legislation to prevent exposures to second hand smoke on restaurant patronage are 


\section{What this paper adds}

The tobacco industry consistently claims that legislation on smoke-free restaurants will damage revenues in the catering industry. Evidence from developed countries shows that, overall, business will remain stable or increase after a total ban. There is strong community support for a totally smoke-free policy in restaurants in Hong Kong, a population with large sex differences in smoking prevalence. A smoke-free policy is likely to increase overall patronage of restaurants. Under the most extreme unfavourable assumptions in this Asia community, the outcome is likely to be neutral in terms of catering business revenues. The predictive factors for the support of totally smoke-free policies were non-smoking status, lower frequency of eating out in restaurants, avoidance of restaurants in the past because of smoking, and experience of discomfort or other adverse reactions from exposure to second hand smoke in restaurants.

consistent with others on the outcome of smoke-free policies in Australia and the USA. They provide policymakers with an objective appraisal of public opinion and the likely impact of tobacco control measures intended to reduce workers and customers exposures to second hand smoke. The findings will strengthen the government's case for new legislation when the bill is debated in the Hong Kong Legislative Council in 2003.

The results support the majority of other studies which have examined staff or customer opinions, business revenues, sales tax receipts, and international tourism and have found no overall negative impact on the catering and hospitality industry, and a significant increase in revenues in some.

\section{ACKNOWLEDGEMENTS}

The survey on which this report is based was funded in part by the Hong Kong Health Services Research Committee (grant number 412016) and the Hong Kong Council on Smoking and Health. Professor Mohsen Janghorbani completed this work while he was visiting research fellow at Hong Kong University. We are grateful for the skilful interview assistance provided by Chu Mei Ling and Tsang Tsui Lan. We wish to thank Mr Marcus Yu for his support and advice, and Dr R Fielding and Mr A Chan for their valuable comments.

\section{Authors' affiliations}

T H Lam, *A J Hedley, S Y Ho, S M McGhee, B Chan, Department of Community Medicine and Unit for Behavioural Sciences, University of Hong Kong, Hong Kong

M Janghorbani, Department of Epidemiology and Biostatistics, School of Public Health, Isfahan University of Medical Sciences, Isfahan, Iran

*AJ Hedley is Chairman of the Hong Kong Council on Smoking and Health, Hong Kong

\section{REFERENCES}

1 US Environmental Protection Agency. Respiratory health effects of passive smoking: lung cancer and other disorders. Washington DC: US Environmental Protection Agency, Office of Health and Environmental Assessment, Office of Atmospheric and Indoor Air Programs, 1992. (Publication No. EPA/600/6-90/006F.

2 Tutt D, Kinnaird B, Rolls J. Introducing smoke-free zones in restaurants. Aust Health Rev 1990;13:122.
3 Hill D. Public opinion about smoking in restaurants and at work. Med J Aust 1986;145:657-8.

4 Siegel M. Involuntary smoking in the restaurant workplace: a review of employee exposure and health effects. JAMA 1993;270:490-3.

5 Americans for Non-smokers' Rights. 100\% Smoke-free ordinances. Berkeley, California: Americans for Non-smokers' Rights; September 1998.

6 Mullins R, Borland R. Preference and requests for smoke-free dining Aust J Public Health 1995;19:100-1.

7 Roberts C, Algert C, Chey T, et al. Community attitudes to smoking in restaurants [letter]. Med J Aust 1992;157:210.

8 Schofield MJ, Considine R, Boyle CA, et al. Smoking controls in restaurants: the effectiveness of self-regulation in Australia. Am J Public Health 1993;83:1284-8.

9 Coalition for a Smoke-free City. Gallup organization public opinion survey on New Yorkers' attitudes about smoke-free dining. New York: Coalition for a Smoke-free City; 1994

10 Mathematica Policy Research Inc. Public opinion surveys on tobacco control policies for the Robert Johnson smokeless state program. Princeton, New Jersey: Mathematica Policy Research Inc, 1995

11 Walker A. Worldwide moves against tobacco promotion. BM 1990;301:458

12 US Department of Health and Human Services. The health consequences of smoking: cancer. A report of the Surgeon General, 1982. Bethesda, Maryland: Public Health Service, Office on Smoking and Health, 1982 (DHHS Publication No (PHS) 82-50179.)

13 Biener L, Siegel M. Behavior intentions of the public after ban on smoking in restaurants and bars. Am J Public Health 1997;87:2042-4.

14 Stanwick RS, Thomson MP, Wilson EF. A survey of Winnipeg restaurant patrons' attitude toward nonsmoking areas. Can J Public Health 1988;79:231-4

15 Glantz SA, Smith LRA. The effect of ordinances requiring smoke-free restaurants and bars on revenues: a follow-up. Am J Public Health 1997;87: 1687-93.

16 Glantz SA, Smith LRA. The effect of ordinances requiring smoke-free restaurants on restaurant sales. Am J Public Health 1994;84:1081-5.

17 Hwang P, Toblas S Kohout S, et al. Assessment of the impact of a $100 \%$ smoke-free ordinance on restaurant sales, West Lake Hill, Texas, 1992-1994. MMWR Morb Mortal Wkly Rep 1995;44:370-2.

18 Sciacca J, Ratliff $M$. Prohibiting smoking in restaurants: effects on restaurant sales. Am J Health Promotion 1998;12:176-84.

19 Glantz SA, Charlesworth A. Tourism and hotel revenues before and after passage of smoke-free restaurant ordinances. JAMA 1999;281:191118

20 Bartosch W, Pope G. The economic effect of smoke-free restaurant policies on restaurant business in Massachusetts. J Public Health Manage Pract 1999:5:53-62.

21 Glantz SA. Smoke-free restaurant ordinances don't affect restaurant business. Period. J Public Health Manage Pract 1999;5:vi-ix.

22 Macdonald H, Glantz S. The political realities of statewide smoking legislation: the passage of California's Assembly Bill 13. Tobacco Control 1997:6:41-54

23 Wakefield $M$, Robert L, Miller C. Perception of the effect of an impending restaurant smoking ban on dining-out experience. Prev Med 1999;29:53-6.

24 Health and Welfare Bureau, Hong Kong. Proposed legislative amendments to smoking (public health) ordinance. Cap 317. Consultation document. The Government of the Hong Kong Special Administrative Region, the People's Republic of China. Health and Welfare Bureau, Government Secretariat. URL: http://www.info.gov.hk/ hwb/

25 Census and Statistics Department. Hong Kong annual digest of statistics 2000. Telephone services table 8.15. Hong Kong: Printing Department, 2000. URL: http://www.info.gov.hk/censtatd/.

26 Waksberg J. Sampling method for random digit dialing. J Am Stat Assoc 1978;73:40-6.

27 Kish L. Survey sampling. New York: Wiley, 1965.

28 Gardner MJ, Altman DG. Statistics with confidence. London: British Medical Association, 1989.

29 Norusis MJ. SPSS regression models for Windows user's guide release 10.0. Chicago, Illinois: SPSS, 1999.

30 Hong Kong Census and Statistics Department. 1996 population by census. Hong Kong: Census and Statistics Department, 1997.

31 Hong Kong Government Health and Welfare Burea. Thematic household survey in the fourth quarter of 2000; a report on pattern of cigarette smoking, June 2001.

32 Philpot SJ, Ryan SA, Torre LE, et al. Effect of smoke-free policies on the behavior of social smokers. Tobacco Control 1999:8:278-81.

33 Corsun DL, Young CA, Enz CA. Should NYC's restaurateurs lighten up? Effects of the city's smoke-free-air act. Cornell Hotel and Restaurant Administration Quarterly 1996;37:26-34. 